\title{
Cardio-Oncology Preclinical Models: A Comprehensive Review
}

\author{
WAFA BOULEFTOUR ${ }^{1}$, BENOITE MERY ${ }^{2}$, ELISE ROWINSKI ${ }^{2}$, \\ CHARLENE RIVIER $^{1}$, ELISABETH DAGUENET ${ }^{3}$ and NICOLAS MAGNE ${ }^{3,4}$ \\ ${ }^{I}$ Medical Oncology Department, Lucien Neuwirth Cancer Institute, Saint Priest en Jarez, France; \\ ${ }^{2}$ Medical Oncology Department, Léon Bérard Cancer Centre, Lyon, France; \\ ${ }^{3}$ Radiotherapy Department, Lucien Neuwirth Cancer Institute, Saint Priest en Jarez, France; \\ ${ }^{4}$ Laboratoire de Radiobiologie Cellulaire et Moléculaire, CNRS UMR 5822, \\ Institut de Physique Nucléaire de Lyon (IPNL), Lyon Medicine University, Lyon, France
}

\begin{abstract}
Cardiotoxicity is a common side effect induced by cancer therapies, which increases the risk of long-term morbidity and mortality in cancer survivors. To date, the mechanism leading to this toxicity is still unclear, thus complicating cardiac safety assessment and predictive factor identification. The advances in technology, particularly regarding radiation therapy and constant development of novel antineoplastic agents, require urgent development of efficient preclinical models to detect drug cardiotoxicity. A myriad of empirical preclinical models have been used to investigate cardiotoxicity, though with limited success. Recently, multicellular spheroid models have gained attention by mimicking the in vivo microenvironment. The aim of this review is to focus on the most relevant preclinical models used to assess antineoplastic drug-and radiotherapy-related cardiotoxicities, with an overview on their current use. It also aims to discuss the possible directions of translational research in the cardio-oncology field.
\end{abstract}

Cardiotoxicity is a common side-effect induced by cancer therapies; it increases the risk of long-term morbidity and mortality in cancer survivors. Indeed, cardiotoxic side-effects caused by antineoplastic drugs can range from asymptomatic

This article is freely accessible online.

Correspondence to: Dr. Bouleftour Wafa, Department of Medical Oncology, Institut de Cancérologie Lucien Newirth Saint Priest en Jarez, 108 bis avenue Albert Raimond, 42270 Saint Priest en Jarez, France. Tel: +33 477917470, Fax: +33 477917497, e-mail: wafa.bouleftour@icloire.fr

Key Words: Cardiotoxicity, antineoplastic drugs, preclinical model, in vivo model, in vitro model, spheroid model, review. reductions in left ventricular ejection fraction (LVEF), to tachycardia and arrhythmias, cardiomyopathy, myocardial infarction, and highly symptomatic congestive heart failure (1).

The real risk of cardiotoxicity was observed after the beginning of clinical use of antineoplastic drugs. Numerous clinical trials have highlighted the cumulative cardiac toxicities of anticancer treatments for hematological malignancies and solid tumors (2). However, the real frequency of cardiac toxicities has not been assessed yet. Indeed, patients with cardiac comorbidities are generally excluded from early phases of clinical trials.

Despite the large use of anthracyclines as cancer treatment, the incidence of doxorubicin acute cardiotoxicity within 2-3 days following its administration has been reported to be about $11 \%$ (3). Conversely, the incidence of chronic doxorubicin cardiotoxicity has been estimated at $1.7 \%$ (4). Likewise, new anticancer drugs, in particular vascular endothelial growth factor (VEGF) pathway inhibitors such as bevacizumab, sunitinib and sorafenib increase the occurrence of myocardial ischemia and have been correlated with hypertension and heart failure $(5,6)$. Moreover, congestive heart failure has been reported in approximately $8 \%$ of patients receiving sunitinib. In addition, administration of immune-checkpoint inhibitors (ICIs) has been shown to cause cardiovascular adverse events, particularly myocarditis (7), while, pericardial disease was the second most commonly reported adverse reaction $(13.6 \%$ of patients treated with ICIs) in the VigiBase database $(8,9)$. Recent reviews have highlighted an increasing incidence of ICI-related cardiotoxicity, particularly acute myocardial infarction and takotsubo syndrome (10). Likewise, the use of chest radiation therapy to treat lymphoma, breast and lung cancer has been associated with an increasing risk of cardiotoxicity leading to cardiovascular complications (11-14), while the combination of antineoplastic drugs and radiotherapy may induce a potential risk of additional cardiac 
toxicities (15). Therefore, it is important to identify the predictive factors of cardiotoxicities related to anti-cancer treatments, in order to adapt patient's treatment (16-18).

It has been shown that free radicals leading to oxidative stress, mitochondrial dysfunction, DNA damage, and apoptosis are involved in the antineoplastic treatmentinduced cardiotoxicity (19); however, the exact mechanism remains unclear. Therefore, it is crucial to better understand the underlying molecular mechanism by using reliable experimental models.

A myriad of empirical preclinical models are used to predict cardiotoxicity, though with fairly limited success. Cardiac electrophysiological effects are assessed using cell lines overexpressing hERG (human ether-a-go-go-related gene) (20). In vivo models are also used for the assessment of the effects of kinase inhibitors (21). This review focuses on the most relevant preclinical models used to assess antineoplastic drugand radiotherapy- related cardiotoxicities with an overview of their current use. Moreover, the possible directions of translational research in the cardio-oncology field are discussed.

\section{In Vitro Models of Cardiotoxicity}

Cell line models represent prominent experimental models to evaluate pharmacokinetics, cell viability, cytotoxicity and drug efficacy for antineoplastic validation. Anticancer drugs have been observed to affect contractility, electrophysiological properties and induce structural toxicities. Almost all validation phases of antineoplastic therapies use cell models. Therefore, several in vitro models have been developed. The most relevant ones with regard to antineoplastic cardiotoxicity assessment will be discussed.

Primary cardiomyocytes. Most studies were performed with cultured primary cardiomyocytes, to assess contraction, ischemia, hypoxia, hypertrophy and drug toxicity. Neonatal rat cardiac ventricular myocytes (NRVM) served as in vitro models to study mechanisms of cardiac pathologies (22). Moreover, the cardiotoxicity of multiple tyrosine kinase inhibitors (TKIs) was assessed on NRVM primary culture (23). When used in the same model, sunitinib and desatinib were more cytotoxic than other TKIs (23). Furthermore, evaluation assays of molecules protecting against doxorubicin cardiotoxicity were carried out in neonatal mouse cardiac ventricular myocyte (NRVM) cultures (24). Conversely, studies with NMVMs are limited to contractile function, handling calcium, and electrophysiology. In NMVM cultures, high levels of metallothionein were shown to induce an inhibition of doxorubicin toxicity (25). Likewise, testosterone was reported to antagonize NMVM senescence induced by doxorubicin (26).

Adult cardiomyocytes provide a powerful model for heart research. Nevertheless, the isolation of these cells remains a very delicate process (27). The mechanism contributing to anthracycline late cardiotoxicity was studied on adult rat cardiomyocyte cultures. Indeed, doxorubicin caused an accumulation of poly-ubiquitinated proteins and autophagosomes causing damage on cardiomyocytes (28). Other studies assessed the doxorubicin effect on contractile function and oxidative stress status of the adult rat cardiomyocyte cells $(29,30)$. These studies showed that doxorubicin resulted in an increase in intracellular $\mathrm{Ca}^{2+}$ concentrations inducing reactive oxygen species (ROS) production (30). Neuregulin-1 $\beta$ attenuated doxorubicininduced alterations and reduced oxidative stress in adult rat ventricular myocytes (ARVM) (29). Antineoplastic-related cardiotoxicities assays on adult mouse cardiomyocytes are limited (21). However, adult cardiomyocytes offer an accurate model, which recapitulates cardiac function as it occurs in the adult heart in vivo.

Human cardiomyocytes provide a more precise model of drug-related cardiotoxicities, compared to animal-dirived cardiomyocytes. Indeed, these cells conserve their morphological integrity and electrophysiological function. A few studies have investigated the cardiotoxic effect of antineoplastic therapy on human cardiomyocytes (31-33). These studies showed that these cells maintained their morphological integrity and electrophysiological properties for a short duration in culture. Due to the scarcity of human cardiac tissue donors and technical difficulties to extract and isolate these cell types, this model is less commonly used (34).

Primary cardiomyocytes are the most relevant model; however, their isolation is time-consuming and costly due to technical difficulties, such as the enzymatic digestion which can induce a disruption of the permeability of the cell membrane $(31,35)$.

Established cell lines. To assess cardiotoxicity, a number of human and rodent cell lines have been developed. One frequently used model to assess cardiac physiology is the H9C2 cardiomyoblast cell line. These cells, isolated from embryonic rat heart ventricle, have shown many similarities to primary cardiomyocytes. H9C2 cell line offers a valuable in vitro model for the investigation of drug metabolizing enzymes of the heart, drug-induced toxicities $(36,37)$ and transmembrane signal transduction (38). Furthermore, H9C2 cells have been validated as a valuable model for cardiac ischemia-reperfusion injury (39). However, these cells have multiple skeletal muscle characteristics and can differentiate into myotube-like structures $(36,38,40)$. This is why the use of this model in cardiac studies is limited. Several studies have assessed doxorubicin-induced cardiotoxicity with $\mathrm{H} 9 \mathrm{C} 2$ cultures (41-44). The cardiac toxicity of doxorubicin, fluorouracil together with adriamycin and cyclophosphamide (FAC), as well as of tyrosine kinase inhibitors has been widely assessed with H9C2 cell lines $(45,46)$. 
Mouse atrial HL-1 cells are also immortalized cells with a cardiac phenotype and widely used as cardiac ischemiareperfusion injury model. These cell lines provide a valuable in vitro model for cardiovascular disease states (47). HL-1 cells have been less used in the evaluation of cardiotoxicities related to antineoplastic molecules. Oxidative stress related to doxorubicin has been assessed through this model (48, 49). In a comparative study, Kuzenetsov et al. demonstrated that $\mathrm{H} 9 \mathrm{C} 2$ cardiomyoblasts are more similar energetically to primary cardiomyocytes than HL-1, and therefore, constitute a more suitable model for cardiac ischemia-reperfusion injury studies (39).

The AC16 human cardiomyocyte cell line is derived from primary cells of human ventricular tissue (50). The cardiotoxic side effects of doxorubicin at cumulative doses were assessed on AC16 cell cultures (51). Regarding cardiac electrophysiological proprieties assessment, cell lines overexpressing hERG (human ether-a-go-go-related gene) are mostly used. Despite the fact that these cell lines are is suitable for the study of electrophysiological properties, these immortal cells do not have the physiological and functional characteristics of cardiomyocytes. To our knowledge, no study has analyzed anti-neoplastic-induced cardiotoxicity using these cell lines so far.

Human pluripotent stem cell derived cardiomyocytes. Human induced pluripotent stem cell derived cardiomyocytes (hiPSC$\mathrm{CMs}$ ) are a revolutionary model in cardio-oncology preclinical research. Indeed, these cardiomyocytes are specific to the donor patient and their generation is unlimited. In this context, hiPSC-CMs derived from breast cancer patients suffering from doxorubicin-induced cardiotoxicity, showed a constant toxicity to doxorubicin (52). Thus, this model can be used to detect the population at greater risk of developing antineoplastic-induced cardiotoxicity. From a functional point of view, hiPSC-CMs exhibit calcium flux, conserve contractile function, and express the majority of ion channels and sarcomere proteins found in the adult heart. The contractile function of hiPSC by motion field imaging (MFI) was monitored along with antineoplastic drug exposure (53). In this model, doxorubicin induced much more cardiotoxicities than erlotinib, a TKI targeting EGFR. Another study using hiPSC-CMs to assess cardiotoxicity of 4 TKIs, demonstrated that each molecule has its own toxicity profile with different mechanisms that led to cardiotoxicity (54). Similarly, Wang et al. demonstrated that TKIs have distinct cardiac side effects in the hiPSC-CMs model (55). Indeed, following sorafenib treatment, oxidative phosphorylation was down-regulated resulting in mitochondrial defects (55). Recently, the effects of trastuzumab on the structural and functional properties of iPSC-CMs from healthy individuals and from patients were assessed (56). Cells derived from patients with severe cardiac dysfunction were more vulnerable to trastuzumab treatment, than healthy iPSC-CMs (56). Despite all these advantages, the use of hiPSC-CM also has drawbacks. These cells remain at an immature state, substantially resembling the fetal phenotype, which induces a structural and electrophysiological variability, such as sarcomeric organization and ion channel density distribution (57). In addition, hiPSC generation remains very expensive and time consuming.

Co-cultured cell lines. Co-culture represents an effective model for drug research as it allows an in-depth monitoring of drug effects on cell-cell interactions. A number of studies have used this model to assess the putative cardiotoxic and proinflammatory effects of immunotherapy. Co-cultures of human cardiomyocytes and lymphocytes were exposed to ipilimumab or nivolumab (58). A significant cardiotoxic effect, related to these ICIs, was observed in co-cultures of lymphocytes and tumor or cardiac cells associated to leukotriene overexpression (58). Similarly, co-cultures of tumor cells or human fetal cardiomyocytes with lymphocytes exposed to pembrolizumab and trastuzumab induced a cardiotoxic effect associated with cardiomyocyte viability reduction (59). Cardiac proinflammatory effects were mediated by overexpression of NF$\mathrm{kB}$ and leukotriene B4 (59). However, even if cell-cell interaction is easier in co-cultures, the complex phenomenon of in vivo cardiophysiopathology cannot be accurately reproduced.

\section{Preclinical Animal Models}

Chemotherapy. Rodent models have been widely used to investigate the various forms of anthracycline-induced cardiotoxicity (60). Forty years ago, Herman et al. demonstrated that Wistar-Kyoto hypertensive rats were much more sensitive to the cardiotoxic effects of doxorubicin than normotensive rats (61). Mouse models were also used to investigate doxorubicin-induced cardiac dysfunction; the mechanisms contributing to this dysfunction were studied with a juvenile DBA/2J mouse model (62). Regarding doxorubicin cardiac toxicity, it has been reported to be different in male and female adult Wistar rats (63). After 7 weeks of doxorubicin administration, males developed major signs of cardiomyopathy with cardiac atrophy, reduced left ventricular ejection fraction and $50 \%$ mortality rate, while female left ventricular ejection was moderately affected (63). Furthermore, mouse xenograft tumor models were developed to assess doxorubicin cardiotoxicity (64). Similar to rodent model, doxorubicin showed more severe cardiotoxicity in the male xenograft model than in the female one (64).

Other animal species such as dogs, mini pigs and rabbits were used to assess anthracycline cardiac toxicities (60). In addition, doxorubicin-induced cardiotoxicity was investigated using a genetically modified mouse model (65). This study identified a potential predictive factor, reporting that patients 
with higher expression of Top $2 \beta$ in their cardiomyocytes may be more susceptible to doxorubicin cardiac toxicities. Zebrafish is another animal model for studying cardiac side effects. Zebrafish embryos exposed to anthracycline daunorubicin, pirarubicin, doxorubicin (DOX), epirubicin and DOX-liposome developed heart defects (66). Early developing zebrafish embryos experienced the same effects as the mammalian models, offering a promising model of drug-induced cardiotoxicity (66). Moreover, zebrafish cardiomyocytes express voltage-gated sodium channels, Ltype and T-type calcium channels and potassium channel, similarly to vertebrates (67). These electrophysiological characteristics of zebrafish model are useful to study drugassociated QT prologation (68). Furthremore, with the advances in genome editing technology, transgenic zebrafish models were developed. Indeed, it has been shown that genetic mutation of CYP1a protected zebrafish against doxorubicin-induced cardiotoxicity (69).

Radiotherapy. Radiation therapy is administered to more than $50 \%$ of cancer patients. Animal models have been used to study cardiac toxicity induced by different radiotherapy regimens, ranging from whole thorax, whole heart and partial heart exposure (70). Lauk et al. showed that rat heart local irradiation with a single dose of over $10 \mathrm{~Gy}$ induced heart disease (71). Moreover, a study that used a genetically modified mouse model to identify the molecular basis of radiation-induced cardiotoxicity demonstrated that p53 functions in endothelial cells to prevent radiation-induced myocardial injury in mice (72). In another study, in which female rats received a 24 Gy localized whole-heart radiation, myocardial strain worsened post-RT, especially at 10-weeks and in lateral regions (68). Combined radiation therapy and antineoplastic drugs have been little studied through animal models. In the 70s, the cardiotoxic effects of adriamycin and radiation therapy were assessed using young New Zealand White rabbits (74). Animals in the combined group (radiation and adriamycin) developed diffuse myocardial fibrosis with greater frequency and severity than animals in the single therapy group (74). In another study, male Sprague-Dawley rats received local heart irradiation ( $9 \mathrm{~Gy}$ ) and oral sunitinib. No early enhanced effects of radiation and sunitinib on cardiac function and structure were observed (75). Currently, patients receive several combinations of antineoplastic drugs and radiation therapy. More experiments are needed to study the impact of this antineoplastic association on cardiac functions.

Targeted therapy. In the era of personalized medicine, targeted therapy (TT) radically changed the outcomes of various cancers. However, TT drugs are associated with significant cardiac toxicity $(76,77)$. Indeed, bevacizumab and sunitinib were shown to induce systemic hypertension and left ventricular systolic dysfunction in young male
C57BL6 mice (78). Experiments using ErbB2-deficient conditional mutant mice demonstated cardiomyopathy related to trastuzumab (79). ErbB2 signaling in cardiomyocytes was found to be essential to prevent dilated cardiomyopathy (73). Zebrafish model was also use to predict sorafenib cardiotoxicity (80). Additionally, cardiotoxic effects of three antiangiogenic antineoplastic drugs -bevacizumab, endostar, and apatinib- were analyzed using transgenic zebrafish embryos and human lung cancer xenotransplantation models (81). Pericardial edema was associated with decreased heart rate with apatinib in this model. Conversely, no obvious side effects were observed with bevacizumab, which was not concordant with the toxicities experienced by cancer patients (81).

Immunotherapy. Nowadays, immunotherapy has emerged as a major antineoplastic treatment. Rare but clinically significant cardiotoxicity has been associated with ICIs. In murine models, programmed cell death-1 (PD-1) deficiency may induce dilated cardiomyopathy (82). Furthermore, $\mathrm{C} 57 \mathrm{Bl} / 6$ mice that were treated with ipilimumab $(15 \mathrm{mg} / \mathrm{kg})$ in compliance to the clinical use of this monoclonal antibody experienced cardiotoxic effects (58). The combined use of pembrolizumab and trastuzumab increased the expression of interleukins by $40-50 \%$, in female $\mathrm{C} 57 \mathrm{Bl} / 6$ mice (59).

Taken together, animal models are widely used to assess cardiotoxicity of antineoplastic drugs. However, these models cannot faithfully recapitulate the complex pathogenesis of cardiotoxicity in cancer patients. Indeed, cancer physiopathology is complicated and animal models are not able to reproduce all patient comorbidities. Furthermore, animal models have different physiology, drug metabolism and gene expression. Genetically modified animals allow a better understanding of the mechanisms of cardiotoxicity induced by antineoplastic treatments. The zebrafish has emerged as a promising model due to its high degree of similarity with human cardiovascular function (68). More studies are needed to validate these models in the cardio-oncology field.

\section{Three-dimensional (3D) Spheroid/Biosensor Model}

Three-dimensional in vitro cell systems are a promising alternative to animal models to assess antineoplastic cardiotoxicity. Numerous types of 3D models have been developed in the cardiovascular field. Contrary to 2D-cultured cardiomyocytes, 3D-cardiac tissue allows high cell density and the interaction between cells and the extracellular matrix. Recent development of perfused 3D cells culture models and organ-on-chip models offers a promising alternative for the investigation of cardiac response to antineoplastic drugs. Polonchuk et al. demonstrated that cardiac spheroid mimics human heart microenvironment (83). This model was based on 
the co-culture of hiPSC, endothelial cells and fibroblasts. Experiments using spheroid models demonstrated that doxorubicin induced oxidative stress associated with an increased endothelial nitric oxide synthase (83). In addition, doxorubicin induced a drastic decrease of cell outgrowth in spheroid-on-a-chip-device (84). Moreover, a recent study using 3D spheroid model demonstrated the protective role of NRF2 against doxorubicin induced cardiotoxicity (85). Nevertheless, spheroid chip format remains cost-effective and requires short training, thus presenting a convenient tool drug evaluation (84).

In a recent study, a cell-based biosensor was developed, integrating electrodes and microelectrodes for cell viability and electrophysiology monitoring, respectively (86). HeLa cells and cardiomyocytes of neonatal rats were cultured on this cell-based biosensor and cardiotoxicity assessment showed that taxol exposure induced a slight effect on cell viability and electrophysiological activity. By contrast, vinblastine had a strong effect on both cell viability and electrophysiological activity (86). To avoid drug absorption by the scaffold material, Arai et al. fabricated a scaffold-free cardiac construct using iPSCs-CMs and a bio-3D printer (87, 88). The same group presented a method to evaluate contractile force of these cardiac constructs (88). Despite the dazzling progress of $3 \mathrm{D}$ cell culture, and the evidence of the clinical pertinence, the use of this model remains limited in the cardio-oncology field. In addition to being less expensive, 2D culture is standardized with large data in the literature, while 3D culture requires technical equipment and expertise and still needs effort to improve accuracy, relevance, and reproducibility (89).

\section{Discussion}

Antineoplastic therapies have greatly improved cancer survival; nevertheless they are associated with acute and chronic cardiac toxicity. The constant development of novel antineoplastic agents and improvement of radiotherapy technologies require urgent development of efficient preclinical models for cardiotoxicity detection. Several in vivo and in vitro preclinical models have been used in cardio-oncology investigations. To date, none of these models has succeeded in reproducing the complex physiopathology of cancer. Moreover, the results of preclinical evaluations of the toxic effects related to antineoplastic drugs using various models have been variable and they are rarely comparable to human data. Most of the studies investigating antineoplastic drug cardiac toxicities were designed with young healthy animals, complicating results transposition to elderly cancer patients (90).

In the era of personalized medicine, the main goal is to provide better treatment efficacy while avoiding toxicities. Patient-derived hiPSC-CMs have proven to be a reliable model for individual doxorubicin-induced cardiotoxicity prediction $(52,91)$. Continuing research should override the immature nature of hiPSC-CM, which is the main drawback of this in vitro model. Furthermore, CRISPR/Cas9 technology has been largely applied to hiPSCs. Through CRISPR/Cas9 forward genetic screening in hiPSCS, Sapp et al. demonstrated that loss of function of transporter proteins SLCO1A2 and SLCO1B3 protects against doxorubicincardiotoxicity (92). Genetic engineering technologies in zebra fish model identified another cardioprotective pathways through CYP1 inhibition (69). Taken together these studies demonstrate that genome editing technologies are revolutionary tools in cardiooncology field. The use of mouse transgenic models allowed a better understanding of doxorubicin-induced cardiotoxicity. Indeed, mice overexpressing neuropeptide $\mathrm{Y}$ treated with doxorubicin had a lower ejection fraction. In this model, doxorubicin at relatively low doses caused significant cardiotoxicity, which was associated with neuropeptide Y overexpression (93). In addition, mice lacking muscle ring finger-1 (MuRF1) were protected from the cardiac atrophy induced by doxorubicin and exhibited no reduction in contractile function (94). Another study using mouse models showed that targeting RAC1 signaling is a promising approach to relive acute and delayed doxorubicin-induced cardiac damage $(95,96)$.

A cellular model using $\mathrm{H} 9 \mathrm{C} 2$ cell line, demonstrated that yangxin granules -a Chinese herbal- had a protective effect against doxorubicin-induced heart failure (97). However, more experimental and clinical studies are warranted to investigate and confirm the cardioprotective action of yangxin. Other preclinical models have demonstrated that fibronectin type III domain-containing 5 (FNDC5) overexpression or irisin treatment can alleviate doxorubicin-induced oxidative stress and cardiomyocyte apoptosis (98). All these preclinical models have identified potential targets to reduce and prevent the cardiotoxic effect induced by doxorubicin.

Cardiotoxicity should be predicted as early as possible and, ideally, before treatment initiation, or before clinical evidence of contractile dysfunction. Recently, the role of microRNA (miRNA) in doxorubicin-induced cardiotoxicity was highlighted (99). In addition to troponin - a circulating marker of heart damage, several in vitro and in vivo studies identified miRNA as diagnostic marker of doxorubicin cardiotoxicity (99). Recently, miRNA modulation was described as a promising therapeutic strategy to counteract cardiotoxicity induced by different oncologic treatments such as epirubicin,bevacizumab, ionizing radiation and radiotherapy (100). Likewise, exosomes in body fluids can serve as biomarkers in the early detection of doxorubicininduced cardiotoxicity (101). However, exosome isolation remains a delicate process and its efficiency and purity are not guaranteed (102).

Lastly, the novel 3D cardiac cell cultures hold great potential in cardiotoxicology research. Spheroid models may 
be a more rational alternative to cell culture, due to the more physiological growth of the cells, despite the limiting factors such as higher cost, more elaborate maintenance requirements and the unsuitability of some cell lines. Several cardiac constructs have emerged, integrating various organotypic microtissues in microfluidic systems. However, further studies are needed to ensure reproducibility and protocol standardization.

In conclusion, cancer therapy-associated cardiotoxicities represent common serious events that may imply fatal complications for patients. To date, none of preclinical models has succeeded in reproducing the complex physiopathology of cancer disease. The development of reliable and effective preclinical models for cardiotoxicity prediction and prevention is essential to improve the longterm cardiac health of cancer patients.

\section{Conflicts of Interest}

The Authors declare no competing financial interests.

\section{Authors' Contributions}

WB and NM contributed to the construction of the review. BM, ER, $\mathrm{CR}$ and $\mathrm{ED}$ contributed to drafting and revision of the manuscript. All Authors read and approved the final manuscript.

\section{Acknowledgements}

The Authors would like to thank Sandrine Sotton for English editing services.

\section{References}

1 Shakir DK and Rasul KI: Chemotherapy induced cardiomyopathy: pathogenesis, monitoring and management. J Clin Med Res 1(1): 8-12, 2009. PMID: 22505958. DOI: 10.4021/jocmr2009.02.1225

2 Seltzer JH, Gintant G, Amiri-Kordestani L, Singer J, Koplowitz LP, Moslehi JJ, Barac A and Yu AF: Assessing cardiac safety in oncology drug development. Am Heart J 214: 125-133, 2019. PMID: 31202099. DOI: 10.1016/j.ahj.2019.04.010

3 Takemura $G$ and Fujiwara H: Doxorubicin-induced cardiomyopathy from the cardiotoxic mechanisms to management. Prog Cardiovasc Dis 49(5): 330-352, 2007. PMID: 17329180. DOI: 10.1016/j.pcad.2006.10.002

4 Chatterjee K, Zhang J, Honbo N and Karliner JS: Doxorubicin cardiomyopathy. Cardiology 115(2): 155-162, 2010. PMID: 20016174. DOI: 10.1159/000265166

5 Touyz RM, Herrmann SMS and Herrmann J: Vascular toxicities with VEGF inhibitor therapies-focus on hypertension and arterial thrombotic events. J Am Soc Hypertens 12(6): 409-425, 2018. PMID: 29703600. DOI: 10.1016/j.jash.2018.03.008

6 Haas NB, Manola J, Ky B, Flaherty KT, Uzzo RG, Kane CJ, Jewett M, Wood L, Wood CG, Atkins MB, Dutcher JJ, Wilding $\mathrm{G}$ and DiPaola RS: Effects of adjuvant sorafenib and sunitinib on cardiac function in renal cell carcinoma patients without overt metastases: Results from ASSURE, ECOG 2805. Clin Cancer Res 21(18): 4048-4054, 2015. PMID: 25967143. DOI: 10.1158/1078-0432.CCR-15-0215

7 Heinzerling L, Ott PA, Hodi FS, Husain AN, Tajmir-Riahi A, Tawbi H, Pauschinger M, Gajewski TF, Lipson EJ and Luke JJ: Cardiotoxicity associated with CTLA4 and PD1 blocking immunotherapy. J Immunother Cancer 4: 50, 2016. PMID: 27532025. DOI: 10.1186/s40425-016-0152-y

8 Michel L, Rassaf T and Totzeck M: Cardiotoxicity from immune checkpoint inhibitors. Int J Cardiol Heart Vasc 25: 100420, 2019. PMID: 31517036. DOI: 10.1016/j.ijcha.2019.100420

9 Upadhrasta S, Elias H, Patel K and Zheng L: Managing cardiotoxicity associated with immune checkpoint inhibitors. Chronic Dis Transl Med 5(1): 6-14, 2019. PMID: 30993259. DOI: 10.1016/j.cdtm.2019.02.004

10 Lyon AR, Yousaf N, Battisti NML, Moslehi J and Larkin J: Immune checkpoint inhibitors and cardiovascular toxicity. Lancet Oncol 19(9): e447-e458, 2018. PMID: 30191849. DOI: 10.1016/S1470-2045(18)30457-1

11 Zhu Q, Kirova YM, Cao L, Arsene-Henry A and Chen J: Cardiotoxicity associated with radiotherapy in breast cancer: A question-based review with current literatures. Cancer Treat Rev 68: 9-15, 2018. PMID: 29777800. DOI: 10.1016/j.ctrv. 2018.03.008

12 Heidenreich PA, Hancock SL, Lee BK, Mariscal CS and Schnittger I: Asymptomatic cardiac disease following mediastinal irradiation. J Am Coll Cardiol 42(4): 743-749, 2003. PMID: 12932613. DOI: 10.1016/s0735-1097(03)00759-9

13 Heidenreich PA, Schnittger I, Strauss HW, Vagelos RH, Lee BK, Mariscal CS, Tate DJ, Horning SJ, Hoppe RT and Hancock SL: Screening for coronary artery disease after mediastinal irradiation for Hodgkin's disease. J Clin Oncol 25(1): 43-49, 2007. PMID: 17194904. DOI: 10.1200/JCO.2006.07.0805

14 Chargari C, Guy JB, Falk AT, Schouver ED, Trone JC, Moncharmont C, Védrine L and Magné N: Cardiotoxicity research in breast cancer patients: past and future. Am J Cardiol 113(8): 1447-1448, 2014. PMID: 24685328. DOI: 10.1016/j.amjcard.2014. 01.421

15 Magné N, Chargari C, MacDermed D, Conforti R, Védrine L, Spano JP and Khayat D: Tomorrow's targeted therapies in breast cancer patients: what is the risk for increased radiation-induced cardiac toxicity? Crit Rev Oncol Hematol 76(3): 186-195, 2010. PMID: 20138541. DOI: 10.1016/j.critrevonc.2010.01.012

16 Chargari C, Kirov KM, Bollet MA, Magné N, Védrine L, Cremades S, Beuzeboc P, Fourquet A and Kirova YM: Cardiac toxicity in breast cancer patients: from a fractional point of view to a global assessment. Cancer Treat Rev 37(4): 321-330, 2011. PMID: 20864260. DOI: 10.1016/j.ctrv.2010.08.007

17 Magné $\mathrm{N}$ and Chargari C: Re: Therapy Insight: anthracyclines and trastuzumab - the optimal management of cardiotoxic side effects. Nat Clin Pract Oncol 5(11): E1, 2008. PMID: 18957967. DOI: $10.1038 /$ ncponc1275

18 Magné N, Largillier R, Marcy PY, Magné J and Namer M: Cardiac toxicity assessment in locally advanced breast cancer treated neoadjuvantly with doxorubicin/paclitaxel regimen. Support Care Cancer 13(10): 819-825, 2005. PMID: 15798914. DOI: $10.1007 / \mathrm{s} 00520-005-0804-9$

19 Altena R, Perik PJ, van Veldhuisen DJ, de Vries EG and Gietema JA: Cardiovascular toxicity caused by cancer treatment: 
strategies for early detection. Lancet Oncol 10(4): 391-399, 2009. PMID: 19341970. DOI: 10.1016/S1470-2045(09)70042-7

20 Braam S, Tertoolen L, Van de stolpe A, Meyer T, Passier R and Mummery C: Prediction of drug-induced cardiotoxicity using human embryonic stem cell-derived cardiomyocytes. Stem Cell Research 4(2): 107-116, 2018. DOI: 10.1016/j.scr.2009.11.004

21 Force T and Kolaja KL: Cardiotoxicity of kinase inhibitors: the prediction and translation of preclinical models to clinical outcomes. Nat Rev Drug Discov 10(2): 111-126, 2011. PMID: 21283106. DOI: $10.1038 / \mathrm{nrd} 3252$

22 Golden HB, Gollapudi D, Gerilechaogetu F, Li J, Cristales RJ, Peng $\mathrm{X}$ and Dostal DE: Isolation of cardiac myocytes and fibroblasts from neonatal rat pups. Methods Mol Biol 843: 205214, 2012. PMID: 22222535. DOI: 10.1007/978-1-61779-5237_20

23 Hasinoff B: The cardiotoxicity and myocyte damage caused by small molecule anticancer tyrosine kinase inhibitors is correlated with lack of target specificity. Toxicology and Applied Pharmacology 244(2): 190-195, 2018. DOI: 10.1016/j.taap. 2009.12.032

24 Berdichevski A, Meiry G, Milman F, Reiter I, Sedan O, Eliyahu S, Duffy HS, Youdim MB and Binah O: TVP1022 protects neonatal rat ventricular myocytes against doxorubicin-induced functional derangements. J Pharmacol Exp Ther 332(2): 413 420, 2010. PMID: 19915070. DOI: 10.1124/jpet.109.161158

25 Wang GW and Kang YJ: Inhibition of doxorubicin toxicity in cultured neonatal mouse cardiomyocytes with elevated metallothionein levels. J Pharmacol Exp Ther 288(3): 938-944, 1999. PMID: 10027829.

26 Altieri P, Barisione C, Lazzarini E, Garuti A, Bezante GP, Canepa M, Spallarossa P, Tocchetti CG, Bollini S, Brunelli C and Ameri P: Testosterone Antagonizes Doxorubicin-Induced Senescence of Cardiomyocytes. J Am Heart Assoc 5(1): e002383, 2016. PMID: 26746999. DOI: 10.1161/JAHA.115.002383

27 Graham EL, Balla C, Franchino H, Melman Y, del Monte F and Das S: Isolation, culture, and functional characterization of adult mouse cardiomyoctyes. J Vis Exp (79): e50289, 2013. PMID: 24084584. DOI: $10.3791 / 50289$

28 Dimitrakis P, Romay-ogando M, Timolati F, Suter $\mathrm{T}$ and Zuppinger C: Effects of doxorubicin cancer therapy on autophagy and the ubiquitin-proteasome system in long-term cultured adult rat cardiomyocytes. Cell and Tissue Research 350(2): 361-372, 2019. DOI: 10.1007/s00441-012-1475-8

29 Timolati F, Ott D, Pentassuglia L, Giraud MN, Perriard JC, Suter TM and Zuppinger C: Neuregulin-1 beta attenuates doxorubicin-induced alterations of excitation-contraction coupling and reduces oxidative stress in adult rat cardiomyocytes. J Mol Cell Cardiol 41(5): 845-854, 2006. PMID: 17005195. DOI: 10.1016/j.yjmcc.2006.08.002

30 Kim SY, Kim SJ, Kim BJ, Rah SY, Chung SM, Im MJ and Kim $\mathrm{UH}$ : Doxorubicin-induced reactive oxygen species generation and intracellular $\mathrm{Ca}^{2+}$ increase are reciprocally modulated in rat cardiomyocytes. Exp Mol Med 38(5): 535-545, 2006. PMID: 17079870. DOI: $10.1038 / \mathrm{emm} .2006 .63$

31 Bistola V, Nikolopoulou M, Derventzi A, Kataki A, Sfyras N, Nikou N, Toutouza M, Toutouzas P, Stefanadis C and Konstadoulakis MM: Long-term primary cultures of human adult atrial cardiac myocytes: cell viability, structural properties and BNP secretion in vitro. Int J Cardiol 131(1): 113-122, 2008. PMID: 18255169. DOI: 10.1016/j.ijcard.2007.10.058
32 Bénardeau A, Hatem SN, Rücker-Martin C, Tessier S, Dinanian S, Samuel JL, Coraboeuf E and Mercadier JJ: Primary culture of human atrial myocytes is associated with the appearance of structural and functional characteristics of immature myocardium. J Mol Cell Cardiol 29(5): 1307-1320, 1997. PMID: 9201617. DOI: 10.1006/jmcc.1996.0366

33 Li RK, Mickle DA, Weisel RD, Carson S, Omar SA, Tumiati LC, Wilson GJ and Williams WG: Human pediatric and adult ventricular cardiomyocytes in culture: assessment of phenotypic changes with passaging. Cardiovasc Res 32(2): 362-373, 1996. PMID: 8796124. DOI: 10.1016/0008-6363(96)00079-x

34 Janssen PM, Lehnart SE, Prestle J and Hasenfuss G: Preservation of contractile characteristics of human myocardium in multi-day cell culture. J Mol Cell Cardiol 31(8): 1419-1427, 1999. PMID: 10423340. DOI: $10.1006 /$ jmcc.1999.0978

35 Bird SD, Doevendans PA, van Rooijen MA, Brutel de la Riviere A, Hassink RJ, Passier R and Mummery CL: The human adult cardiomyocyte phenotype. Cardiovasc Res 58(2): 423-434, 2003. PMID: 12757876. DOI: 10.1016/s00086363(03)00253-0

36 Zordoky BN and El-Kadi AO: $\mathrm{H} 9 \mathrm{c} 2$ cell line is a valuable in vitro model to study the drug metabolizing enzymes in the heart. J Pharmacol Toxicol Methods 56(3): 317-322, 2007. PMID: 17662623. DOI: 10.1016/j.vascn.2007.06.001

37 Watkins SJ, Borthwick GM and Arthur HM: The H9C2 cell line and primary neonatal cardiomyocyte cells show similar hypertrophic responses in vitro. In Vitro Cell Dev Biol Anim 47(2): 125-131, 2011. PMID: 21082279. DOI: 10.1007/s11626010-9368-1

38 Hescheler J, Meyer R, Plant S, Krautwurst D, Rosenthal W and Schultz G: Morphological, biochemical, and electrophysiological characterization of a clonal cell $(\mathrm{H} 9 \mathrm{c} 2)$ line from rat heart. Circ Res 69(6): 1476-1486, 1991. PMID: 1683272. DOI: 10.1161/ 01.res.69.6.1476

39 Kuznetsov AV, Javadov S, Sickinger S, Frotschnig S and Grimm M: H9c2 and HL-1 cells demonstrate distinct features of energy metabolism, mitochondrial function and sensitivity to hypoxiareoxygenation. Biochim Biophys Acta 1853(2): 276-284, 2015. PMID: 25450968. DOI: 10.1016/j.bbamcr.2014.11.015

40 Kimes BW and Brandt BL: Properties of a clonal muscle cell line from rat heart. Exp Cell Res 98(2): 367-381, 1976. PMID: 943302. DOI: 10.1016/0014-4827(76)90447-x

41 Dallons M, Schepkens C, Dupuis A, Tagliatti V and Colet JM: New insights about doxorubicin-induced toxicity to cardiomyoblast-derived $\mathrm{H} 9 \mathrm{C} 2$ cells and dexrazoxane cytoprotective effect: Contribution of in vitro ${ }^{1} \mathrm{H}-\mathrm{NMR}$ metabonomics. Front Pharmacol 11: 79, 2020. PMID: 32153402. DOI: 10.3389/fphar.2020.00079

42 Helal M, Alcorn J and Bandy B: Doxorubicin cytotoxicity in differentiated H9c2 cardiomyocytes: Evidence for acute mitochondrial superoxide generation. Cardiovasc Toxicol 21(2): 152-161, 2021. PMID: 32910361. DOI: 10.1007/s12012-02009606-1

43 Tan X, Wang DB, Lu X, Wei H, Zhu R, Zhu SS, Jiang H and Yang ZJ: Doxorubicin induces apoptosis in H9c2 cardiomyocytes: role of overexpressed eukaryotic translation initiation factor 5A. Biol Pharm Bull 33(10): 1666-1672, 2010. PMID: 20930373. DOI: 10.1248/bpb.33.1666

44 Wang H, Wang H, Liang EY, Zhou LX, Dong ZL, Liang P, Weng QF and Yang M: Thrombopoietin protects H9C2 cells 
from excessive autophagy and apoptosis in doxorubicin-induced cardiotoxicity. Oncol Lett 15(1): 839-848, 2018. PMID: 29403560. DOI: $10.3892 / 01.2017 .7410$

45 Lekes D, Szadvari I, Krizanova O, Lopusna K, Rezuchova I, Novakova M, Novakova Z, Parak T and Babula P: Nilotinib induces ER stress and cell death in H9c2 cells. Physiol Res 65(Suppl 4): S505-S514, 2016. PMID: 28006933. DOI: 10.33549/physiolres.933504

46 Zeng X, Cai H, Yang J, Qiu H, Cheng Y and Liu M: Pharmacokinetics and cardiotoxicity of doxorubicin and its secondary alcohol metabolite in rats. Biomed Pharmacother 116: 108964, 2019. PMID: 31102935. DOI: 10.1016/j.biopha.2019. 108964

47 Elshenawy OH, Anwar-Mohamed A, Abdelhamid G and El-Kadi AO: Murine atrial HL-1 cell line is a reliable model to study drug metabolizing enzymes in the heart. Vascul Pharmacol 58(4): 326333, 2013. PMID: 23268359. DOI: 10.1016/j.vph.2012.12.002

48 Asensio-López MC, Soler F, Pascual-Figal D, Fernández-Belda F and Lax A: Doxorubicin-induced oxidative stress: The protective effect of nicorandil on HL-1 cardiomyocytes. PLoS One 12(2): e0172803, 2017. PMID: 28245258. DOI: 10.1371/journal.pone. 0172803

49 Strigun A, Wahrheit J, Niklas J, Heinzle E and Noor F: Doxorubicin increases oxidative metabolism in HL-1 cardiomyocytes as shown by $13 \mathrm{C}$ metabolic flux analysis. Toxicol Sci 125(2): 595-606, 2012. PMID: 22048646. DOI: $10.1093 /$ toxsci/kfr298

50 Davidson MM, Nesti C, Palenzuela L, Walker WF, Hernandez E, Protas L, Hirano M and Isaac ND: Novel cell lines derived from adult human ventricular cardiomyocytes. J Mol Cell Cardiol 39(1): 133-147, 2005. PMID: 15913645. DOI: 10.1016/j.yjmcc.2005.03.003

51 Yoon CS, Kim HK, Mishchenko NP, Vasileva EA, Fedoreyev SA, Stonik VA and Han J: Spinochrome D attenuates doxorubicininduced cardiomyocyte death via improving glutathione metabolism and attenuating oxidative stress. Mar Drugs 17(1): 2, 2018. PMID: 30577438. DOI: 10.3390/md17010002

52 Burridge PW, Li YF, Matsa E, Wu H, Ong SG, Sharma A, Holmström A, Chang AC, Coronado MJ, Ebert AD, Knowles JW, Telli ML, Witteles RM, Blau HM, Bernstein D, Altman RB and Wu JC: Human induced pluripotent stem cell-derived cardiomyocytes recapitulate the predilection of breast cancer patients to doxorubicin-induced cardiotoxicity. Nat Med 22(5): 547-556, 2016. PMID: 27089514. DOI: 10.1038/nm.4087

53 Sakamoto K, Sakatoku K, Sugimoto S, Iwasaki N, Sano Y, Yamaguchi $\mathrm{M}$ and Kurokawa J: Continued exposure of anticancer drugs to human iPS cell-derived cardiomyocytes can unmask their cardiotoxic effects. J Pharmacol Sci 140(4): 345349, 2019. PMID: 31521491. DOI: 10.1016/j.jphs.2019.08.005

54 Doherty KR, Wappel RL, Talbert DR, Trusk PB, Moran DM, Kramer JW, Brown AM, Shell SA and Bacus S: Multi-parameter in vitro toxicity testing of crizotinib, sunitinib, erlotinib, and nilotinib in human cardiomyocytes. Toxicol Appl Pharmacol 272(1): 245-255, 2013. PMID: 23707608. DOI: 10.1016/j.taap. 2013.04.027

55 Wang H, Sheehan RP, Palmer AC, Everley RA, Boswell SA, Ron-Harel N, Ringel AE, Holton KM, Jacobson CA, Erickson AR, Maliszewski L, Haigis MC and Sorger PK: Adaptation of human iPSC-derived cardiomyocytes to tyrosine kinase inhibitors reduces acute cardiotoxicity via metabolic reprogramming. Cell Syst 8(5): 412-426.e7, 2019. PMID: 31078528. DOI: 10.1016/j.cels.2019.03.009

56 Kitani T, Ong SG, Lam CK, Rhee JW, Zhang JZ, Oikonomopoulos A, Ma N, Tian L, Lee J, Telli ML, Witteles RM, Sharma A, Sayed N and Wu JC: Human-induced pluripotent stem cell model of trastuzumab-induced cardiac dysfunction in patients with breast cancer. Circulation 139(21): 2451-2465, 2019. PMID: 30866650. DOI: 10.1161/CIRCULATIONAHA.118.037357

57 Magdy T, Schuldt AJT, Wu JC, Bernstein D and Burridge PW: Human induced pluripotent stem cell (hiPSC)-derived cells to assess drug cardiotoxicity: Opportunities and problems. Annu Rev Pharmacol Toxicol 58: 83-103, 2018. PMID: 28992430. DOI: 10.1146/annurev-pharmtox-010617-053110

58 Quagliariello V, Passariello M, Rea D, Barbieri A, Iovine M, Bonelli A, Caronna A, Botti G, De Lorenzo C and Maurea N: Evidences of CTLA-4 and PD-1 blocking agents-induced cardiotoxicity in cellular and preclinical models. J Pers Med 10(4): 179, 2020. PMID: 33086484. DOI: 10.3390/jpm 10040179

59 Quagliariello V, Passariello M, Coppola C, Rea D, Barbieri A, Scherillo M, Monti MG, Iaffaioli RV, De Laurentiis M, Ascierto PA, Botti G, De Lorenzo C and Maurea N: Cardiotoxicity and pro-inflammatory effects of the immune checkpoint inhibitor Pembrolizumab associated to Trastuzumab. Int J Cardiol 292: 171-179, 2019. PMID: 31160077. DOI: 10.1016/j.ijcard.2019. 05.028

60 Herman EH and Ferrans VJ: Preclinical animal models of cardiac protection from anthracycline-induced cardiotoxicity. Semin Oncol 25(4 Suppl 10): 15-21, 1998. PMID: 9768819.

61 Herman EH, el-Hage AN, Ferrans VJ and Ardalan B: Comparison of the severity of the chronic cardiotoxicity produced by doxorubicin in normotensive and hypertensive rats. Toxicol Appl Pharmacol 78(2): 202-214, 1985. PMID: 4035676. DOI: 10.1016/0041-008x(85)90284-4

62 Zhu W, Shou W, Payne RM, Caldwell R and Field LJ: A mouse model for juvenile doxorubicin-induced cardiac dysfunction. Pediatr Res 64(5): 488-494, 2008. PMID: 18614963. DOI: 10.1203/PDR.0b013e318184d732

63 Moulin M, Piquereau J, Mateo P, Fortin D, Rucker-Martin C, Gressette M, Lefebvre F, Gresikova M, Solgadi A, Veksler V, Garnier A and Ventura-Clapier R: Sexual dimorphism of doxorubicin-mediated cardiotoxicity: potential role of energy metabolism remodeling. Circ Heart Fail 8(1): 98-108, 2015. PMID: 25420486. DOI: 10.1161/CIRCHEARTFAILURE.114.001180

$64 \mathrm{Oh} \mathrm{S}$ and Jung J: Sex-dependent liver cancer xenograft models for predicting clinical data in the evaluation of anticancer drugs. Lab Anim Res 37(1): 10, 2021. PMID: 33632339. DOI: 10.1186/s42826-021-00087-z

65 Zhang S, Liu X, Bawa-Khalfe T, Lu LS, Lyu YL, Liu LF and Yeh ET: Identification of the molecular basis of doxorubicininduced cardiotoxicity. Nat Med 18(11): 1639-1642, 2012. PMID: 23104132. DOI: 10.1038/nm.2919

66 Han Y, Zhang JP, Qian JQ and Hu CQ: Cardiotoxicity evaluation of anthracyclines in zebrafish (Danio rerio). J Appl Toxicol 35(3): 241-252, 2015. PMID: 24853142. DOI: 10.1002/jat.3007

67 Baker K, Warren KS, Yellen G and Fishman MC: Defective "pacemaker" current (Ih) in a zebrafish mutant with a slow heart rate. Proc Natl Acad Sci U S A 94(9): 4554-4559, 1997. PMID: 9114028. DOI: 10.1073/pnas.94.9.4554 
68 Lane S, More LA and Asnani A: Zebrafish models of cancer therapy-induced cardiovascular toxicity. J Cardiovasc Dev Dis 8(2): 8, 2021. PMID: 33499052. DOI: 10.3390/jcdd8020008

69 Lam PY, Kutchukian P, Anand R, Imbriglio J, Andrews C, Padilla H, Vohra A, Lane S, Parker DL Jr, Cornella Taracido I, Johns DG, Beerens M, MacRae CA, Caldwell JP, Sorota S, Asnani A and Peterson RT: Cyp1 inhibition prevents doxorubicin-induced cardiomyopathy in a zebrafish heartfailure model. Chembiochem 21(13): 1905-1910, 2020. PMID: 32003101. DOI: $10.1002 /$ cbic.201900741

70 Schlaak RA, SenthilKumar G, Boerma M and Bergom C: Advances in preclinical research models of radiation-induced cardiac toxicity. Cancers (Basel) 12(2): 415, 2020. PMID: 32053873. DOI: $10.3390 /$ cancers 12020415

71 Lauk S, Kiszel Z, Buschmann J and Trott KR: Radiationinduced heart disease in rats. Int J Radiat Oncol Biol Phys 11(4): 801-808, 1985. PMID: 3980275. DOI: 10.1016/0360-3016(85) 90314-1

72 Lee CL, Moding EJ, Cuneo KC, Li Y, Sullivan JM, Mao L, Washington I, Jeffords LB, Rodrigues RC, Ma Y, Das S, Kontos CD, Kim Y, Rockman HA and Kirsch DG: p53 functions in endothelial cells to prevent radiation-induced myocardial injury in mice. Sci Signal 5(234): ra52, 2012. PMID: 22827996. DOI: 10.1126/scisignal.2002918

73 Ibrahim EH, Baruah D, Croisille P, Stojanovska J, Rubenstein JC, Frei A, Schlaak RA, Lin CY, Pipke JL, Lemke A, Xu Z, Klaas A, Brehler M, Flister MJ, Laviolette PS, Gore EM and Bergom C: Cardiac magnetic resonance for early detection of radiation therapy-induced cardiotoxicity in a small animal model. JACC CardioOncol 3(1): 113-130, 2021. PMID: 33912843. DOI: $10.1016 /$ j.jaccao.2020.12.006

74 Fajardo LF, Eltringham JR and Steward JR: Combined cardiotoxicity of adriamycin and x-radiation. Lab Invest 34(1): 86-96, 1976. PMID: 1246126.

75 Sridharan V, Thomas CJ, Cao M, Melnyk SB, Pavliv O, Joseph J, Singh SP, Sharma S, Moros EG and Boerma M: Effects of local irradiation combined with sunitinib on early remodeling, mitochondria, and oxidative stress in the rat heart. Radiother Oncol 119(2): 259-264, 2016. PMID: 27072940. DOI: 10.1016/j.radonc .2016 .03 .027

76 Van Leeuwen MT, Luu S, Gurney H, Brown MR, Pearson SA, Webber K, Hunt L, Hong S, Delaney GP and Vajdic CM: Cardiovascular toxicity of targeted therapies for cancer: an overview of systematic reviews. JNCI Cancer Spectr 4(6): pkaa076, 2020. PMID: 33392444. DOI: 10.1093/jncics/pkaa076

77 Svoboda M, Poprach A, Dobes S, Kiss I and Vyzula R: Cardiac toxicity of targeted therapies used in the treatment for solid tumours: a review. Cardiovasc Toxicol 12(3): 191-207, 2012. PMID: 22528816. DOI: 10.1007/s12012-012-9164-0

78 Bordun KA, Premecz S, daSilva M, Mandal S, Goyal V, Glavinovic T, Cheung M, Cheung D, White CW, Chaudhary R, Freed DH, Villarraga HR, Herrmann J, Kohli M, Ravandi A, Thliveris J, Pitz M, Singal PK, Mulvagh S and Jassal DS: The utility of cardiac biomarkers and echocardiography for the early detection of bevacizumab- and sunitinib-mediated cardiotoxicity. Am J Physiol Heart Circ Physiol 309(4): H692-H701, 2015. PMID: 26092985. DOI: 10.1152/ajpheart.00172.2015

79 Crone SA, Zhao YY, Fan L, Gu Y, Minamisawa S, Liu Y, Peterson KL, Chen J, Kahn R, Condorelli G, Ross J Jr, Chien $\mathrm{KR}$ and Lee KF: ErbB2 is essential in the prevention of dilated cardiomyopathy. Nat Med 8(5): 459-465, 2002. PMID: 11984589. DOI: $10.1038 / \mathrm{nm} 0502-459$

80 Cheng H, Kari G, Dicker AP, Rodeck U, Koch WJ and Force $\mathrm{T}$ : A novel preclinical strategy for identifying cardiotoxic kinase inhibitors and mechanisms of cardiotoxicity. Circ Res 109(12): 1401-1409, 2011. PMID: 21998323. DOI: 10.1161/CIRCR ESAHA.111.255695

81 Jin Y, Wei L, Jiang Q, Song X, Teng C, Fan C, Lv Y, Liu Y, Shen W, Li L, Huang D and Xin T: Comparison of efficacy and toxicity of bevacizumab, endostar and apatinib in transgenic and human lung cancer xenograftzebrafish model. Sci Rep 8(1): 15837, 2018. PMID: 30367145. DOI: 10.1038/s41598-01834030-5

82 Nishimura H, Okazaki T, Tanaka Y, Nakatani K, Hara M, Matsumori A, Sasayama S, Mizoguchi A, Hiai H, Minato N and Honjo T: Autoimmune dilated cardiomyopathy in PD-1 receptor-deficient mice. Science 291(5502): 319-322, 2001. PMID: 11209085. DOI: 10.1126/science.291.5502.319

83 Polonchuk L, Chabria M, Badi L, Hoflack JC, Figtree G, Davies $\mathrm{MJ}$ and Gentile $\mathrm{C}$ : Cardiac spheroids as promising in vitro models to study the human heart microenvironment. Sci Rep 7(1): 7005, 2017. PMID: 28765558. DOI: 10.1038/s41598-017-06385-8

84 Christoffersson J, Meier F, Kempf H, Schwanke K, Coffee M, Beilmann M, Zweigerdt R and Mandenius CF: A cardiac cell outgrowth assay for evaluating drug compounds using a cardiac spheroid-on-a-chip device. Bioengineering (Basel) 5(2): 36, 2018. PMID: 29734702. DOI: 10.3390/bioengineering5020036

85 Tomlinson L, Lu ZQ, Bentley RA, Colley HE, Murdoch C, Webb SD, Cross MJ, Copple IM and Sharma P: Attenuation of doxorubicin-induced cardiotoxicity in a human in vitro cardiac model by the induction of the NRF-2 pathway. Biomed Pharmacother 112: 108637, 2019. PMID: 30798127. DOI: 10.1016/j.biopha.2019.108637

86 Wei X, Gu C, Li H, Pan Y, Zhang B, Zhuang L, Wan H, Hu N and Wang P: Efficacy and cardiotoxicity integrated assessment of anticancer drugs by a dual functional cell-based biosensor. Sensors and Actuators B: Chemical 283: 881-889, 2019. DOI: 10.1016/j.snb.2018.12.085

87 Arai K, Murata D, Verissimo AR, Mukae Y, Itoh M, Nakamura A, Morita $S$ and Nakayama K: Fabrication of scaffold-free tubular cardiac constructs using a Bio-3D printer. PLoS One 13(12): e0209162, 2018. PMID: 30557409. DOI: 10.1371/ journal.pone.0209162

88 Arai K, Murata D, Takao S, Nakamura A, Itoh M, Kitsuka T and Nakayama K: Drug response analysis for scaffold-free cardiac constructs fabricated using bio-3D printer. Sci Rep 10(1): 8972, 2020. PMID: 32487993. DOI: 10.1038/s41598020-65681-y

89 Zuppinger C: 3D cardiac cell culture: A critical review of current technologies and applications. Front Cardiovasc Med 6: 87, 2019. PMID: 31294032. DOI: 10.3389/fcvm.2019.00087

90 Madonna R, Cadeddu C, Deidda M, Mele D, Monte I, Novo G, Pagliaro P, Pepe A, Spallarossa P, Tocchetti CG, Zito C and Mercuro G: Improving the preclinical models for the study of chemotherapy-induced cardiotoxicity: a Position Paper of the Italian Working Group on Drug Cardiotoxicity and Cardioprotection. Heart Fail Rev 20(5): 621-631, 2015. PMID: 26168714. DOI: $10.1007 / \mathrm{s} 10741-015-9497-4$

91 Sharma A, McKeithan WL, Serrano R, Kitani T, Burridge PW, Del Álamo JC, Mercola M and Wu JC: Use of human induced 
pluripotent stem cell-derived cardiomyocytes to assess drug cardiotoxicity. Nat Protoc 13(12): 3018-3041, 2018. PMID: 30413796. DOI: 10.1038/s41596-018-0076-8

92 Sapp V, Aguirre A, Mainkar G, Ding J, Adler E, Liao R, Sharma S and Jain M: Genome-wide CRISPR/Cas9 screening in human iPS derived cardiomyocytes uncovers novel mediators of doxorubicin cardiotoxicity. Sci Rep 11(1): 13866, 2021. PMID: 34230586. DOI: 10.1038/s41598-021-92988-1

93 Mattila M, Söderström M, Ailanen L, Savontaus E and Savontaus M: The effects of neuropeptide Y overexpression on the mouse model of doxorubicin-induced cardiotoxicity. Cardiovasc Toxicol 20(3): 328-338, 2020. PMID: 31811615. DOI: 10.1007/s12012-019-09557-2

94 Willis MS, Parry TL, Brown DI, Mota RI, Huang W, Beak JY, Sola M, Zhou C, Hicks ST, Caughey MC, D’Agostino RB Jr, Jordan J, Hundley WG and Jensen BC: Doxorubicin exposure causes subacute cardiac atrophy dependent on the striated muscle-specific ubiquitin ligase MuRF1. Circ Heart Fail 12(3): e005234, 2019. PMID: 30871347. DOI: 10.1161/CIRCHEART FAILURE.118.005234

95 Ma J, Wang Y, Zheng D, Wei M, Xu H and Peng T: Rac1 signalling mediates doxorubicin-induced cardiotoxicity through both reactive oxygen species-dependent and -independent pathways. Cardiovasc Res 97(1): 77-87, 2013. PMID: 23027656. DOI: $10.1093 / \mathrm{cvr} / \mathrm{cvs} 309$

96 Ohlig J, Henninger C, Zander S, Merx M, Kelm M and Fritz G: Rac1-mediated cardiac damage causes diastolic dysfunction in a mouse model of subacute doxorubicin-induced cardiotoxicity. Arch Toxicol 92(1): 441-453, 2018. PMID: 28710503. DOI: $10.1007 / \mathrm{s} 00204-017-2017-7$

97 Ren D, Li F, Cao Q, Gao A, Ai Y and Zhang J: Yangxin granules alleviate doxorubicin-induced cardiotoxicity by suppressing oxidative stress and apoptosis mediated by AKT/GSK3 $\beta / \beta$-catenin signaling. J Int Med Res 48(8): 300060520945161,2020 . PMID: 32780664. DOI: 10.1177/0300060520945161
98 Zhang X, Hu C, Kong CY, Song P, Wu HM, Xu SC, Yuan YP, Deng W, Ma ZG and Tang QZ: FNDC5 alleviates oxidative stress and cardiomyocyte apoptosis in doxorubicin-induced cardiotoxicity via activating AKT. Cell Death Differ 27(2): 540555, 2020. PMID: 31209361. DOI: 10.1038/s41418-019-0372-z

99 Ruggeri C, Gioffré S, Achilli F, Colombo GI and D'Alessandra Y: Role of microRNAs in doxorubicin-induced cardiotoxicity: an overview of preclinical models and cancer patients. Heart Fail Rev 23(1): 109-122, 2018. PMID: 28944400. DOI: 10.1007/s10741-017-9653-0

100 Pellegrini L, Sileno S, D'Agostino M, Foglio E, Florio MC, Guzzanti V, Russo MA, Limana F and Magenta A: MicroRNAs in cancer treatment-induced cardiotoxicity. Cancers (Basel) 12(3): 704, 2020. PMID: 32192047. DOI: 10.3390/cancers 12030704

101 Tian C, Yang Y, Bai B, Wang S, Liu M, Sun RC, Yu T and Chu $\mathrm{XM}$ : Potential of exosomes as diagnostic biomarkers and therapeutic carriers for doxorubicin-induced cardiotoxicity. Int J Biol Sci 17(5): 1328-1338, 2021. PMID: 33867849. DOI: 10.7150/ijbs.58786

$102 \mathrm{Xu}$ JY, Chen GH and Yang YJ: Exosomes: A rising star in falling hearts. Front Physiol 8: 494, 2017. PMID: 28751864. DOI: $10.3389 /$ fphys.2017.00494
Received June 10, 2021

Revised September 27, 2021

Accepted September 29, 2021 